\title{
Miliary Brain Metastasis-A Rare Pattern of Metastases from Breast Cancer
}

\author{
Venkata Pradeep Babu Koyyala ${ }^{1} \quad$ Sumit Goyal ${ }^{2} \quad$ Ankush Jajodia $^{3}$ Varun Goel ${ }^{1}$ \\ B. P. Amrith ${ }^{1}$ Satyajeet Soni ${ }^{1}$ Dinesh Chandra Doval ${ }^{1}$
}

${ }^{1}$ Department of Medical Oncology, Rajiv Gandhi Cancer Institute and Research Centre, New Delhi, India

2Department of Medical Oncology, Head of Unit, Rajiv Gandhi Cancer Institute and Research Centre, New Delhi, India

${ }^{3}$ Department of Radiology, Rajiv Gandhi Cancer Institute and Research Centre, New Delhi, India

\section{South Asian J Cancer 2020;9:188-189.}

A 50-year-old female presented to our hospital with left-sided nipple discharge for the past 2 months. On evaluation, she was found to have locally advanced invasive ductal cancer of the left breast. Immunohistochemistry revealed estrogen, progesterone receptor status as negative and testing for Her-2 was $3+$. She underwent neoadjuvant chemotherapy with TCH (trastuzumab, carboplatin, and taxane) protocol followed by modified radical mastectomy, adjuvant radiotherapy, and maintenance trastuzumab for 1 year. Fourteen months after the completion of maintenance therapy, she was brought to emergency room with a history of convulsions at her home. Contrastenhanced magnetic resonance imaging (MRI) brain revealed miliary lesions distributed in her entire brain parenchyma. Positron emission tomography-computed tomography (CT) was done that showed extensive skeletal and lung metastasis. She was given whole-brain radiotherapy and was started on palliative chemotherapy ( - Fig. 1 ).

The miliary pattern of metastasis to the brain is a very rare phenomenon and usually seen on MRI as multiple tumor nodules in perivascular distribution, usually associated with lung cancer. Miliary brain metastases from breast cancer are very rare. There was one such reported case in the literature. ${ }^{1}$ Contrast-enhanced MRI brain is an important modality to evaluate a suspected case of metastases to the brain. This pattern can be easily missed on CT scan and noncontrast MRI brain scan. ${ }^{2}$ The peculiar aspect of such
Address for correspondence Venkata Pradeep Babu Koyyala, Department of Medical Oncology, Rajiv Gandhi Cancer Institute and Research Centre, New Delhi, India

(e-mail: pradeepbabu.koyyala@gmail.com).

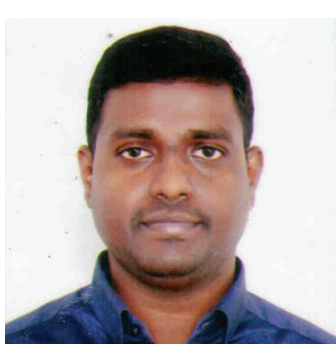

Dr Venkata Pradeep Babu Koyyala

metastases is that these lesions are not associated with perilesional edema or compressive effects. ${ }^{3}$ Important differential diagnoses for such lesions are cryptococcosis, miliary brain tuberculosis, and neurocysticercosis. Pathological diagnosis is the gold standard. ${ }^{4}$ The presence of synchronous systemic metastasis and the clinic radiological correlation is pivotal in making such diagnosis.

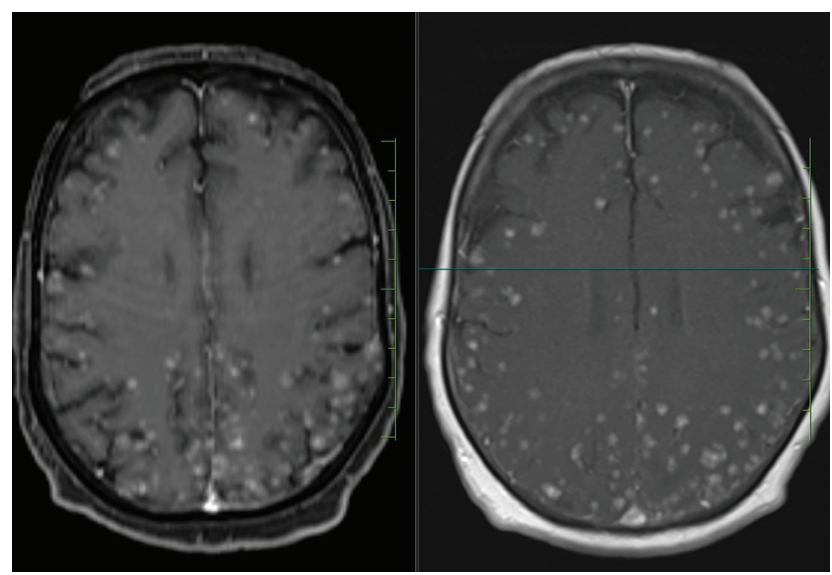

Fig. 1 Magnetic resonance imaging of the brain-postcontrast (both left and right)-reveals multiple subcentimetric tiny enhancing lesions in bilateral cerebral hemispheres-suggestive of metastasis.

How to cite this article: Babu Koyyala VP, Goyal S, Jajodia A, Goel V, Amrith BP, Soni S, Doval DC. Miliary Brain Metastasis-A Rare Pattern of Metastases from Breast Cancer. South Asian I Cancer 2020;9(3):188-189.

DOI https://doi.org/10.1055/s-0041-1723106 ISSN 2278-330X.
(C) 2020. MedIntel Services Pvt Ltd.

This is an open access article published by Thieme under the terms of the Creative Commons Attribution-NonDerivative-NonCommercial-License, permitting copying and reproduction so long as the original work is given appropriate credit. Contents may not be used for commercial purposes, or adapted, remixed, transformed or built upon. (https://creativecommons.org/licenses/by-nc-nd/4.0/).

Thieme Medical and Scientific Publishers Private Ltd A-12, Second Floor, Sector -2, NOIDA -201301, India 
Financial Support and Sponsorship

Nil.

Conflicts of Interest

There are no conflicts of interest.

Acknowledgment

This study was supported by the Rajiv Gandhi Cancer Institute and Research Centre, New Delhi.

\section{References}

1 Cools D, Parizel PM, Dekeyzer S. Miliary brain metastases from primary breast carcinoma: a case report. Acta Neurol Belg 2020;120(1):175-176
2 Bekiesińska-Figatowska M, Kuczyńska-Zardzewiały A, Klepacka T, et al. Miliary brain metastases from papillary adenocarcinoma of the lung - unusual MRI pattern with histopathologic correlation. Pol J Radiol 2013;78(3):57-60

3 Ribeiro HB, Paiva TF Jr, Mamprin GP, Gorzoni ML, Rocha AJ, Lancellotti CL. Carcinomatous encephalitis as clinical presentation of occult lung adenocarcinoma: case report. Arq Neuropsiquiatr 2007;65(3B) :841-844

4 Kahveci R, Gürer B, Kaygusuz G, Sekerci Z. Miliary brain metastases from occult lung adenocarcinoma: Radiologic and histopathologic confirmation. J Neurosci Rural Pract 2012; 3(3):386-389 